\title{
Point Pattern Analysis as Tool for Digital Geoarchaeology - A Case Study of Megalithic Graves in Schleswig-Holstein, Germany
}

\author{
Daniel Knitter and Oliver Nakoinz
}

\begin{abstract}
In this contribution we apply different methods of spatial and geomorphometric analysis in order to present a general approach of data exploration in areas where detailed local information is absent. Our data are based on locations of megalithic graves from Funnel Beaker societies (3700-2800 BCE) in the area of Schleswig-Holstein, Germany. Using these locations, we apply methods of point pattern analysis in order to reconstruct the spatial processes that created the sample: We use density based measures to show the influence of first order effects on the dataset. While first order effects are related to the underlying areal characteristics of the point locations and hence are determinant of their intensity, second-order effects are the result of interactions between points. We conduct distance related approaches, e.g. focusing on nearest neighbor characteristics, in order to investigate the interaction between the points. The point pattern analyses is complemented by integrating geomorphometric measures that are indirectly indicative for some general environmental conditions, even in prehistoric times. This helps (a) to relate first-order effects to societal or environmental features and (b) to understand the specific pattern of interactions between the points. The necessary raw data in form of digital elevation models are freely available for large parts of the globe. All analyses are conducted using free and open source software in order to provide their limitless application.
\end{abstract}

Daniel Knitter

Freie Universität Berlin, Department of Earth Science, Physical Geography, Malteserstraße 74100, 12249 Berlin, e-mail:daniel.knitterefu-berlin.de

Oliver Nakoinz

Christian-Albrechts-Universität, Institut für Ur- und Frühgeschichte, Johanna-Mestorf-Straße 2-6, 24118 Kiel (DFG-Heisenbergfellow Na 687/1-1) e-mail: oliver.nakoinz@ufg. uni-kiel.de 


\section{Introduction}

In this study we aim to present different tools for spatial data analyses that are especially useful in areas where detailed local information is absent; for instance areas of short research history or areas that are not accessible due to political reasons. Our objective is to present a simple workflow that integrates tools from point pattern as well as geomorphometric analyses in order to get a better understanding of the processes that influenced the spatial pattern we observe. Furthermore, we want to discuss some general characteristics of spatial data that make them special.

In order to check the effectiveness of our spatial analytical tools we use a dataset of megalithic graves from Funnel Beaker societies located in the area of SchleswigHolstein, Germany. These are well investigated and allow to prove whether the conclusions we draw from our spatial analyses are a valuable complement of digital geoarchaeological research.

\subsection{Why are spatial data special?}

Spatial data are special because they do not fulfil one of the most common prerequisites of conventional statistical analyses: they are not random, i.e. stochastically independent. This leads to different problems (collection after [O'Sullivan and Unwin, 2010, 34]):

- Spatial autocorrelation is a measure of the importance of a location. It measures to which degree the characteristics at a certain location-or in the study area as a whole-are indicative for other locations in the area. The concept is closely related to Tobler's first law of geography (at least for positive autocorrelation): "(...) everything is related to everything else, but near things are more related than distant things" [Tobler, 1970, 236]. This means that it is more likely that points next to each other have similar or comparable characteristics of e.g. elevation than points that are distant. Local similarities are used to describe and differentiate space. For instance, an area of high concentration of people may be called settlement; a wetland area of low $\mathrm{pH}$-values, dense vegetation and high organic carbon content may be called swamp, etc. The law also indicates that this holds true for all spatial data. If spatial phenomena would vary randomly through space spatial data would be meaningless [O'Sullivan and Unwin, 2010, 35]. There are different techniques that allow to assess the importance of a location-hence spatial autocorrelation-in an analyses, i.e. Moran's I as well as Geary's C (e.g. [Lloyd, 2011, 80-82]).

- The modifiable areal unit problem arises when spatial data are compiled or acquired on a certain level of detail but are analysed in aggregated, areal-modified form [O'Sullivan and Unwin, 2010, 36-38]. For instance, ceramics are counted as single finds but their distribution is reported in terms of ceramics' sum per survey grid cell. This grid cell is a modifiable areal unit that is arbitrary in terms of 
the investigated object. This can lead to problems in subsequent analyses because the unit of aggregation, i.e. our arbitrary survey grid cell, influences the outcome of the analysis. This kind of problem arises also by comparing archaeological sites, like megalithic graves, with environmental features, like natural regions (see Fig. 11). The comprehensive discussion of this issue by [Openshaw, 1984, 4-5, 10-11] shows that different aggregation schemes-e.g. different grid cell sizes or shapes-have a very strong effect on correlation measures.

- The common statistical problem of ecological fallacy is often related to modifiable areal units. It occurs when a statistical relationship at one level of aggregation is assumed to be present because it is present at another [O'Sullivan and Unwin, 2010 39]. Thinking of some archaeological sites that might occur more frequently at higher elevated locations, this observation does not allow us to conclude that those sites are located there because these locations seek higher visibility. It might also be due to the need of a lower groundwater table, to flood risk reduction or creation [Schütt et al., 2002]. Hence, data on occurrence of archaeological sites in different altitudes can only support the conclusion that these are often more elevated in relation to their surroundings.

- Before the start of a spatial analyses it is necessary to decide on which geographic scale the analysis will be conducted because this affects what we are able observe. The sample of this study are megalithic graves, represented as points. This already implies that this scale is too small to, for instance, investigate the orientation of the megalithic monuments. Furthermore, investigating the characteristics of megaliths as points, only gives one measure-e.g. their altitude-although they cover a certain area, i.e. a certain range of altitudes.

- Space is not uniform; accordingly, processes measured in space can be heterogeneous although their characteristics did not change. This is an induced spatial dependence [Borcard et al., 2011, 229]. In terms of megalithic graves this may be seen when one considers a higher population density in a certain area, therefore more settlements and as a result more megalithic graves. Their occurrence is now linked to the higher population density and not, as one could suspect, better circumstances for their construction.

- Edge effects are related to the issue of non-uniformity and arise when an artificial boundary is imposed on a study area [Diggle, 2013, 9]. In the present case the artificial boundary is the area of the modern federal state of Schleswig-Holstein in Germany. This can produce asymmetries in the data since points in the center of the study area can have more nearby observation than those at the edge of the study area.

Many of these points may sound trivial. Nevertheless, it is important to be aware of them since they directly influence the results. Spatial data are the result of processes. In analysing them it is possible to detect functional relationships. But these do not infer causality (see [Ahnert, 2003, 19-20]. Hence, it needs to be discussed continuously, whether these processes are the actual reason of the configuration of spatial data or just an artefact of the analytical approach.

In the frame of this article we use two types of spatial data: One type are point pattern data, as represented by megalithic graves. In this case-like many other in 
reality - we have nothing more to describe and analyze than the graves' locations, since chronological, functional, cultural, etc. information are absent or homogeneous.

Point patterns are the result of processes that are influenced by (a) first-order effects, i.e. the point's location is influenced by the underlying area's structure but not by the location of other points [Wiegand and Moloney, 2004, 210]; (b) second-order effects that occur when the location of a point is influenced by the presence or absence of other points [Wiegand and Moloney, 2004, 210]. Point pattern analyses are common in ecological studies (e.g. [Legendre and Legendre, 2012, Wiegand and Moloney, 2013 |); up to now there are only few applications in archaeological contexts (e.g. [Knitter et al., 2014]).

The other type of spatial data used here are geomorphometric data, i.e. different derivatives of a digital elevation model (DEM). These geomorphometric parameter raster describe the topographic characteristics in spatially continuous form and allow us to draw indirect conclusions on the boundary conditions of location selection in the study area. The integration of DEM related parameters in (digital geo-) archaeological investigations is very common since the 1990s and often used in predictive modelling approaches (e.g. [Verhagen, 2007, Kvamme, 2006]).

\subsection{Case study}

\subsubsection{Natural characteristics of the study area}

The natural characteristics of Schleswig-Holstein are mainly the result of the last two glaciations, i.e. the Weichselian glaciation $(115,000-11,600 \mathrm{a}$ BP) and the Saale glaciation (300,000-130,000a BP) [Litt et al., 2007, 34,46]. In general, three natural regions can be separated: (1) the marsh regions, (2) the geest regions, and (3) the young, heavily undulating regions of east of Schleswig-Holstein ([Stewig, 1982, 18], [Schmidtke, 1995]).

The marsh regions are the youngest areas, formed during the Holocene by continuous up-silting of the intertidal zone- $\mathrm{a}$ in general natural process that was accelerated by human intervention due to the creation of polders. These areas, as we see them today did not exists during the time of Funnel Beaker societies ([Stewig, 1982. 35-42], [Schmidtke, 1995, 86ff]). Since these areas were not inhabitable, no megalithic graves can be found there (Fig 1 1 , category c; Fig 1 b, categories d, f, n, o, p).

East of the marsh area the geest-regions are located (Fig 1 a, category b; Fig 1 b, categories b-c, e, g, k, m, q, s). These are characterised by glacial deposits and can be subdivided in Hohe Geest-areas comprised of terminal and ground moraine deposits from the Saale glaciation as well as Niedere Geest-areas, incised into the geest and formed by glacio-fluvial activities as a result of the melting of the Weichselian ice-sheet in the east, leading to widespread sandur deposits in the glacial meltwater valleys draining to the west [Liedtke and Marcinek, 2002, 438-440]. The Niedere 
Geest sinks gently under the marsh areas. In contrast, marked cliffs can occur between the marsh and the Hohe Geest-regions due to former abrasion at the seashore or during storm tide periods [Stewig, 1982, 27-34]. Due to periglacial processes, Hohe Geest-regions were levelled and marked relief differences are present only at the border to the marsh as well as Niedere Geest-regions [Schmidtke, 1995, 78].

The eastern part of Schleswig-Holstein was covered by the ice of the Weichselian glaciation that created a very heterogeneous and complex topography with diverse series of terminal moraines, interrelated by lakes or local sandurs, escers and kames (Fig 1 1a, category a; Fig 1 $\mathrm{b}$, categories a, h, i-j, t-u). The soils on moraine material are the most fertile of the entire region ([Stewig, 1982, 18-26], [Schmidtke, 1995, 40ff], [Liedtke and Marcinek, 2002, 433-435]).

\subsubsection{Megalithic graves of Funnel Beaker societies}

Megalithic graves are above ground visible monuments consisting of upright and capstones [Müller, 2014, 182]. Starting in the $5^{\text {th }}$ millennium BCE the tradition to build megaliths started in South-West Europe and was distributed along the coasts to reach the Baltic Sea in the $4^{\text {th }}$ millennium BCE. At this time the sea reached its present level [Schmidtke, 1995, 72]. In the study area megalithic graves are present since 3650 BCE, i.e. about 500 years after Neolithisation commenced and connected with the occurrence of early Funnel Beakers [Müller, 2011, 8, 10]. Based on ceramic style and decoration, different societal groups can be distinguished. Altogether these create the complex of Funnel Beaker societies spreading from Southern Scandinavia to Central Europe (Fig. 2).

The research area belongs to the North Group of Funnel Beaker societies where the megalithic phase corresponds to the Middle Neolithic period (3300 cal BCE $2800 \mathrm{cal}$ BCE). The main phase of megaliths' construction was around $3100 \mathrm{BCE}$ [Müller, 2011, 15,17]. Megalithic graves in the Funnel Beaker societies of the North Group are attended to the construction of causewayed enclosures [Müller, 2011, 29]. They can be typologically sequenced into Urdolmen, extended dolmen and passage graves [Müller, 2011, 31,34]. Since megaliths solely rely on slabstones and dry masonry walls their construction necessitates a supportive mound that might have also served as a ramp during the building phase [Müller, 2011, 34].

The dataset consists of 2792 individual megalithic graves in the study area of Schleswig-Holstein. In general it is assumed that more than 3000 of them occur in the area, although most of them are already destroyed. From the known locations only 867 offer more detailed archaeological information and only 188 of them can be seen as well preserved [Lüth, 2011, 117]. An exact dating of the monuments is difficult since they served as collective cemeteries where burials from different periods occur. Furthermore, many of the megalithic graves were destroyed and reused as burial places during the Late Neolithic, especially by the Single Grave culture. As a result the role of megalithic graves within the Funnel Beaker societies is not yet clear [Lüth, 2011, 117,119]. Nevertheless, they seem to be more than just cemeteries. First of all they are clear indicators for former settlements since they were sited 


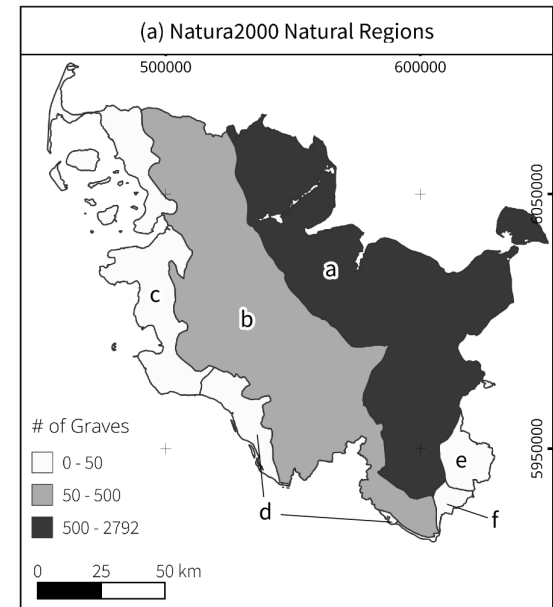

(a) Hügelland (b) Geest (c) Marschen \& Nordseeinseln (d) Unterelbeniederung (Elbmarsch) (e) Mecklenburgische Seenplatte (f) Mecklenburg-Brandenburgisches Platten- \& Hügelland, Luchland

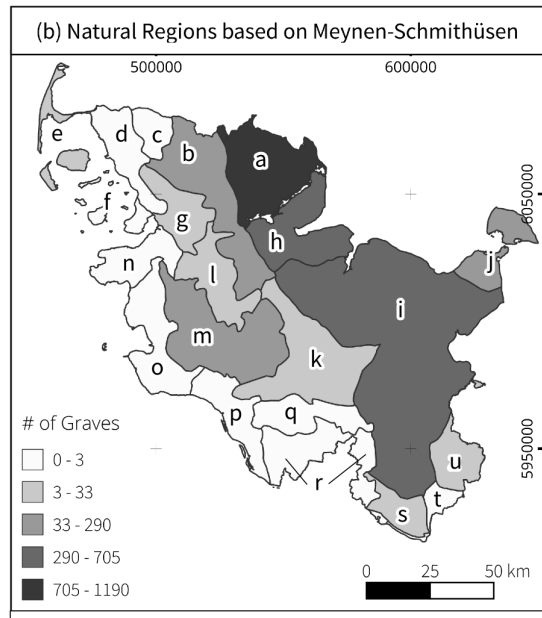

(a) Angeln (b) Schleswiger Vorgeest (c) Lecker Geest (d) Nordfriesische Marsch (e) Nordfriesische Geest inseln (f) Nordfriesische Marschinseln \& Halligen (g) Bredstedt-Husumer Geest (h) Schwansen, Dänischer Wohld u. Amt Hütten (i) Ostholsteinisches Hügel- \& Seenland (j) Nordoldenburg \& Fehmarn

(k) Holsteinische Vorgeest (l) Eider-Treene-Niederung (m) Heide-Itzehoer Geest ( $n$ ) Eiderstedter Marsch (o) Dithmarscher Marsch (p) Holsteinische Elbmarschen (q) Barmstedt-Kisdorfer Geest ( $r$ ) Hamburger Ring (s) Lauenburger Geest ( $\mathrm{t}$ ) Südwestmecklenburgische Niederungen (mit Sanderflächen und Lehm-

platten) (u) Westmecklenburgisches Seenhügelland

Fig. 1: Natural Regions in Schleswig-Holstein and the number of megalithic graves. Most of megalithic graves are located in the northeast and east. The modifiable areal unit problem gets obvious in comparing (a) and (b). The absence of megalithic graves in the marsh-related natural regions corresponds to the fact that these areas were not inhabitable during occupation period of Funnel Beaker societies. (data kindly provided by Federal Agency for Nature Conservation; (a) based on [Ssymank, 1994]; (b) based on [Meynen and Schmithüsen, 1962])

in close vicinity to them. Local site-specific studies also revealed some insights about their locational characteristics (after [Lüth, 2011, 119-122]:

- they are concentrated on fine-grained, fertile soils;

- they are located along streams, fords, near lakes or at the coast; all these locations are preferable for traffic;

- they are located at exposed positions on hills, high-banks of rivers, cliff-costs; all these locations have the character of prominent topographic lines;

- building material, in the form of glacial erratics needs to be available. 


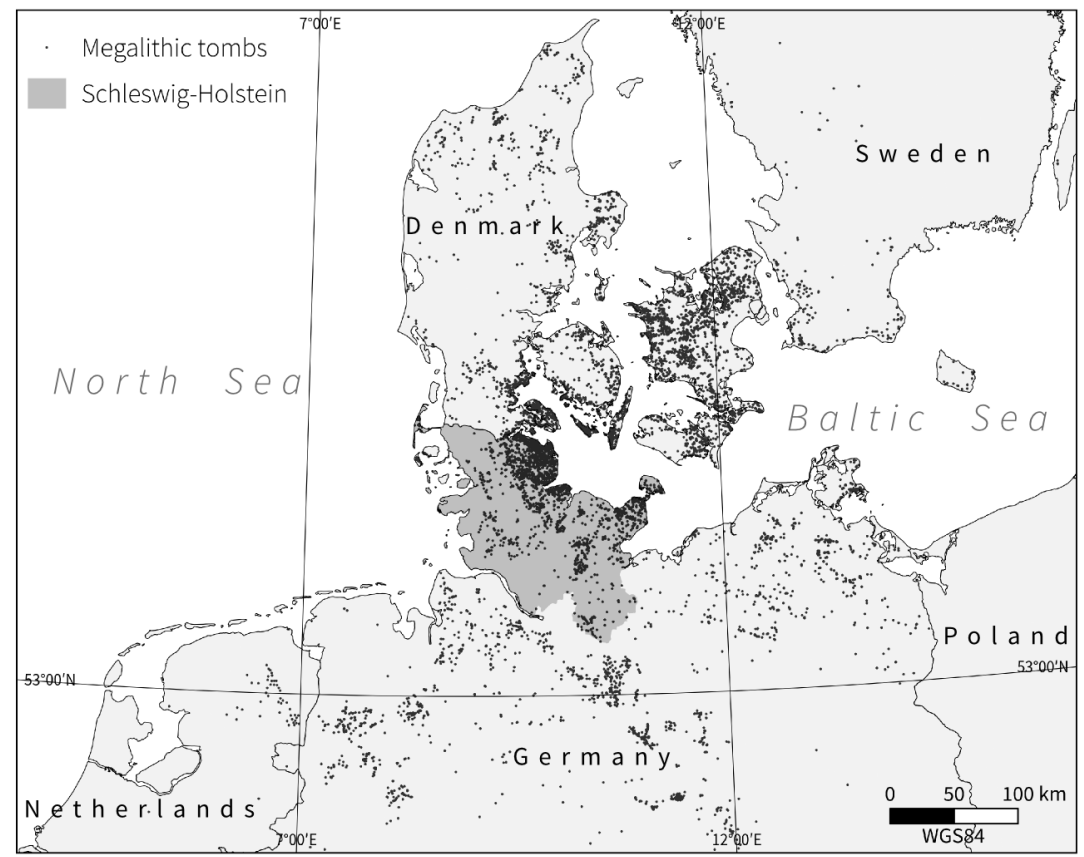

Fig. 2: Megalithic graves of Funnel Beaker societies in northern Europe and southern Scandinavia (based on [Fritsch et al., 2010, Müller, 2014])

These conditions are present in the young, strongly undulating regions in the east of Schleswig-Holstein. Nevertheless, there are also high concentrations of megalithic graves in the Hohe Geest-regions that only partially offer the same conditions as compiled for the young moraine areas (compare Fig. 2 and Fig. 1 .

\section{Methods}

\subsection{Point pattern analyses}

Focusing on spatial data without special attributes, like size or amount of ceramic shards, there is only the location left to analyze. The locations of the megalithic graves form our point pattern. 


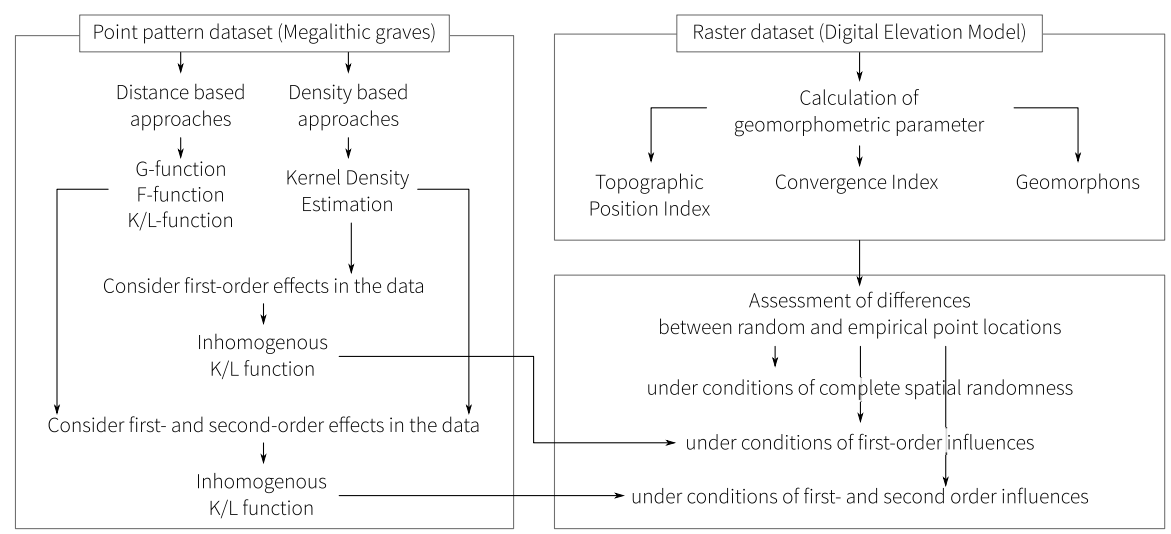

Fig. 3: Workflow of the applied methods; it is based entirely on following opensource software packages: left part and lower right part: R [R Core Team, 2013] with packages sp [Pebesma and Bivand, 2005], rgdal [Bivand et al., 2015], spat stat [Baddeley and Turner, 2005], raster [Hijmans, 2015], ggplot2 [Wickham, 2009]; upper right part: SAGA GIS [Böhner et al., 2006] and GRASS GIS [Neteler et al., 2012]

A point pattern consists of a set of event $\mathrm{S}^{1}, S=\left(s_{1}, s_{2}, \ldots, s_{n}\right)$, in a defined research region $A$ of size $\alpha$; an event $s_{i}$ describes the occurrence of objects of interest at a specific location by geographic coordinates $\left(x_{i}, y_{i}\right)$. The definition of the research region-that corresponds to a modifiable areal unit—influences subsequent analyses. Furthermore, in defining a point pattern it is assumed that all relevant entities are included in the pattern. Both aspects are problematic in archaeological studies due to the fragmentary nature of the source material.

The events constituting a point pattern might be influenced by first-order as well as second-order effects. A point pattern analysis (Fig. 3) allows to a certain degree to separate these influences, though an exact and definite differentiation is not possible [O'Sullivan and Unwin, 2010, 124].

\subsubsection{Density based approach—Kernel density estimation}

First-order effects become evident in the event density, i.e. the process' intensity [Diggle, 2013, 10]. Absolute location is determinant and a clear variation across space shall be visible. The methods applicable to detect first-order effects are density based measures of point patterns. In the present case, we conduct a kernel density estimation [Bivand et al., 2008, 165-168]. The basic idea behind this approach

\footnotetext{
${ }^{1}$ Note that the term event is used here in the technical sense of spatial point pattern analysis: In a spatial point pattern locations are referred to as events in order to distinguish them from other points of the region in question [Diggle, 2013. 1]
} 
is that there is a density at any location, not just at the location of events. This creates a continuous representation of intensity from a set of events allowing (a) to detect high-density spots and (b) to check whether the process is first-order non-stationary, i.e. it shows only local variations from the mean intensity but not an overall trend across the region, as well as (c) to link point objects to other spatially continuous geographical data [O'Sullivan and Unwin, 2010, 68-71].

The density is estimated by applying a kernel function on events in a region that is centred at the location where the estimate is to be made. We use a Gaussian function which weights nearby events more strongly than distant ones. The resulting kernel density estimation is an estimate of the intensity function of the process that generated the phenomena observed [Baddeley and Turner, 2015, 278]:

$$
\hat{\lambda}_{p}=e(p) \sum_{i} k\left(x_{i}-p\right) ; k=f(x, \mu, \sigma)=\frac{1}{\sigma \sqrt{2 \pi}} e^{-\frac{(x-\mu)^{2}}{2 \sigma^{2}}}
$$

where $k$ is the Gaussian smoothing kernel-with standard mean $\mu$ and variable kernel bandwidth, i.e. standard deviation $\sigma-e(p)$ is an edge correction factor, and $p$ is the kernel's location.

It gets obvious that the kernel bandwidth $\sigma$ is crucial for the resulting intensity: a too large value will blur the result and omit local details while a too small bandwidth will omit a potential general trend. Hence, for every research questions the most suitable bandwidth values need to be discovered-a process that in general requires experimentation [Bivand et al., 2008, 166]. In this study we use three different kernel sizes:

- a large kernel with bandwidth of $10,000 \mathrm{~m}$ in order to show a potential trend within the data;

- an empirical kernel whose size equals three times the mean nearest-neighbour distance of the megaliths, i.e. approximately $1500 \mathrm{~m}$;

- a small kernel with bandwidth of $500 \mathrm{~m}$ that will highlight areas where megalithic graves are clustered;

The calculations are conducted using the density function in the spatstatpackage [Baddeley and Turner, 2005].

\subsubsection{Distance based approach-G, F, K, and L function}

Second-order effects refer to distance-dependent interactions between events, hence relative location is important [Diggle, 2013, 57f]. In order to investigate potential interactions between events, distance-based approaches are applied. The simplest is the G-function that investigates the cumulative frequency distribution of nearestneighbour distances [O'Sullivan and Unwin, 2010, 132]. More specifically it calculates what fraction of all nearest-neighbour distances $d_{\min }\left(s_{i}\right)$ in the pattern is less than $d$ [O'Sullivan and Unwin, 2010, 132]: 


$$
G(d)=\frac{\#\left\{d_{\min }\left(s_{i}\right)\right\} \leq d}{n} .
$$

The function's shape provides information about the way the events are spread. If events are clustered $G(d)$ increases rapidly at short distances; if events are evenly spaced $G(d)$ increases slowly up to the distance where most events are spread and increases rapidly afterwards. While the G-function is useful to investigate interactions between events, it does not provide information about the event characteristics in relation to the research region. To get this the F-function is used O'Sullivan and Unwin, 2010, 133]. In applying the function point locations anywhere in the study region are randomly selected and the minimum distance of these to any event in the pattern is determined:

$$
F(d)=\frac{\#\left\{d_{\min }\left(p_{i}, s\right)\right\} \leq d}{m},
$$

where $d_{\min }$ is the minimum distance from location $p_{i}$ in the randomly selected set to any event in the point pattern $s$. The F-function behaves different then the Gfunction for clustered and even patterns: In a clustered pattern-where a large area of the research region is empty- $F(d)$ rises slowly for short distances but stronger for larger distances. In case of an evenly spaced pattern there is a sharp increase of $F(d)$ at the beginning, because the proportion of empty space is small.

There is a shortcoming in applying the G- and F-functions: they only take nearest-neighbour distances into account [Bivand et al., 2008, 161-162]. This is a problem especially in clustered point patterns where the nearest-neighbour functions are very short and might mask a more general structure within the data.

To overcome these restrictions the K-function, known as Ripley's K, is employed that uses all distances between events [Ripley, 2004, 159]. It draws circles $C$ of different radius $d$ around events $s_{i}$. Within each circle the events are counted and the mean count for all events is calculated and divided by the overall mean of the research regions' event density [O'Sullivan and Unwin, 2010, 135]:

$$
K(d)=\frac{\sum_{i=1}^{n} \#\left\{S \in C\left(s_{i}, d\right)\right\}}{n \lambda} .
$$

Since the K-function implements more information than the G- or F-function the resulting plots can offer more insights in the event interactions-like event separation in a regular pattern.

In order to stabilise the variance and to make visual comparisons easier it is common to conduct a square root transformation of the K-function, known as Lfunction [Illian et al., 2008, 95].

$$
L(d)=\sqrt{\frac{K(d)}{\pi}} .
$$

Furthermore, we modify the L-function by substracting the radius $d$ from all values of $L(d)$ [O'Sullivan and Unwin, 2010, 147]. Due to this the theoretical distribution 
corresponds to a straight line at level zero. Positive values are indicative for aggregation, since more events than expected by the theoretical model occur at corresponding distances. Negative values indicate the opposite, since less events as expected are present.

The calculations of the G-, F-, K- and L-functions are conducted using the envelope function in the spat stat-package [Baddeley and Turner, 2005] with default configuration and 99 simulations. The Null-model of the simulations is a complete spatial random process, i.e. a process without first- and second-order effects.

\subsubsection{Data influenced by first- and/or second-order effects}

Up to this stage all distance based approaches assumed the intensity function to be constant and the events in the point pattern independent from the spatial characteristics and location of other events. Nevertheless, due to the non-uniformity of space, such conditions practically do not occur in geographic reality. If solely first-order effects influence the location of events an inhomogeneous or non-stationary point pattern is present ([O'Sullivan and Perry, 2013, 42], [Bivand et al., 2008, 165]).

In order to estimate the characteristics of the point pattern under the influence of first-order effects, we use the inhomogeneous K-function that is a direct generalisation of a non-stationary point process with non-constant intensity [Baddeley et al., 2000, 332]. As in the stationary case we calculate the L-function, i.e. the square root transformation of the inhomogeneous K-function. The parameter for of non-constant intensity equals the result of the kernel density estimation with large bandwidth since it is representative for an overall data-inherent trend.

In general it is difficult to decided whether first- or second-order effects caused the observed point pattern. In order to differentiate between first- and second-order effects artificial point patterns are used that correspond to different Null-models [Diggle, 2013, 99ff]:

- including no first- or second-order effects-also called complete spatial randomnessi.e. event locations are independent of area conditions and the location of other events; we use the function rpoi spp from the spat st at-package [Baddeley and Turner, 2005] with an intensity that is similar to the overall intensity of the megalithic graves.

- including first- but no second-order effects; in this case the random points are created using the same intensity function that was used as determinant in the inhomogeneous case, i.e. the first-order effects mirror the overall trend in the data distribution; as in the previous case the rpoispp function from the spat statpackage [Baddeley and Turner, 2005] is used, but now the intensity is a raster representing the results of the kernel density estimation with large kernel.

- including first- and second-order effects; first-order effects are the same than in the previous case but now there is also interaction between events due to a tendency to cluster. This is realised using the Thomas cluster process, a generalisation of the Neymann-Scott cluster process, where parent points are replaced by 
clusters of offspring points whose locations being isotropic Gaussian displacements from the cluster parent location [Thomas, 1949]. The artificial point pattern is created applying the rThomas-function from the package spatstat [Baddeley and Turner, 2005] with the same intensity as in the previous case and a homogeneous offspring with intensity 2 that is comparable to the intensity of megalithic grave clusters (Fig. 4).

\subsection{Raster analyses}

In order to get an understanding of the topographic characteristics of the megaliths locations we use a digital elevation model (DEM) with a resolution of $90 \times 90 \mathrm{~m}$, derived from SRTM data that is processed to provide a seamless continuous topography surface [Jarvis et al., 2008]. These data are the least error prone for the research area available free of charge, as compared to other free available digital elevation models that offer a higher spatial resolution like Aster or the recently available SRTM1 data (both types of data are available at http: / / earthexplorer. usgs.gov/).

In analysing DEMs we employ methods from geomorphometry, the science of quantitative geometric land-surface analysis [Pike et al., 2009, 3]. We use these techniques in order to get spatially continuous information on the surface characteristics that help us to describe the location of the megalithic graves in context of the natural environment. The larger a landform the longer its existence [Ahnert, 1981]. Based on this rule we do not focus on the very local scale but on the regional scale where the general character of topography is comparable between the time of Funnel Beaker societies and today. Nevertheless, this generalisation is not valid for large parts of the marsh areas since these were made by humans later. Therefore, they are not considered in the subsequent analyses.

\subsubsection{Topographic Position Index}

The Topographic Position Index (TPI), developed by [Guisan et al., 1999, Weiss, 2001], measures the relative topographic position of a cell as the difference between the elevation in this cell and the mean elevation in a predetermined neighbourhood, i.e. moving window [De Reu et al., 2013, 39]. TPI values larger than zero represent locations whose elevation is higher than the average of their surroundings, what holds true e.g. for hills and ridges. Negative TPI values occur at locations that are lower than their surroundings, like e.g. valleys or pits. Flat areas as well as constantly inclined slopes have TPI values near zero.

The Topographic Position Index is inherently scale-dependent. Therefore, the selection of the size of the moving window has a direct influence on the results. By integrating the TPI results for differently sized moving windows, it is possible to create slope position and landform classifications (e.g. [Tagil and Jenness, 2008]). 
We focus our interest on the relative location in terms of ridges or valleys, therefore we only use one moving window with an outer circle radius of $2500 \mathrm{~m}$. TPI is calculated using the Saga GIS module Topographic Position Index [Böhner et al., 2006].

\subsubsection{Convergence Index}

The Convergence Index employs the exposition of neighbouring cells in order to parameterise flow convergence and divergence. It is advantageous to plan curvature since it does not depend on absolute elevation differences [Olaya and Conrad, 2009. 301]. Similar to the TPI, we use it as a measure for relative topographic location since high values correspond to strong flow divergence, e.g. at ridges, while small values correspond to flow convergence, e.g. in depressions. We calculate the parameter using the Saga GIS module Convergence Index [Koethe and Lehmeier, 1996, Böhner et al., 2006].

\subsubsection{Geomorphons}

Besides the continuous geomorphometric measures a landform classification based on Geomorphons [Jasiewicz and Stepinski, 2013] is employed to measure topographic characteristics in qualitative categories. Geomorphons are based on the idea that a landform element can be regarded as the specific spatial arrangement of elevation values in a selected area. Based on this analogy, the method utilises the concept of Local Ternary Patterns, originally developed for texture classification, to identify local landform elements. The resulting geomorphons are fundamental micro-structures of the landscape [Jasiewicz and Stepinski, 2013, 148]. We use the GRASS GIS extension geomorphons to calculate this parameter for landforms smaller than $1 \mathrm{~km}$ [Stepinski and Jasiewicz, 2011, Jasiewicz and Stepinski, 2013].

\section{Results}

\subsection{Density based analysis of megalithic graves}

The results of the kernel density estimation show different patterns: the large kernel (Fig. 4a) indicates that there is a general trend within the data that decreases from northeast to southwest. The empirical kernel (Fig. 4p) shows an area of high density in the northeast but also parts of moderate density that stretch throughout the region, e.g. the zone of moderate density that runs from the western edge of the high density area in southeastern direction. This line corresponds to the transition between the geest areas (Fig. 1 19, category b) and the young moraine area (Fig. 19, category a). 
The small kernel (Fig. 4k) illustrates the location of clusters of megalithic graves. Though the majority of these is located in the northeast, they occur throughout the entire region.
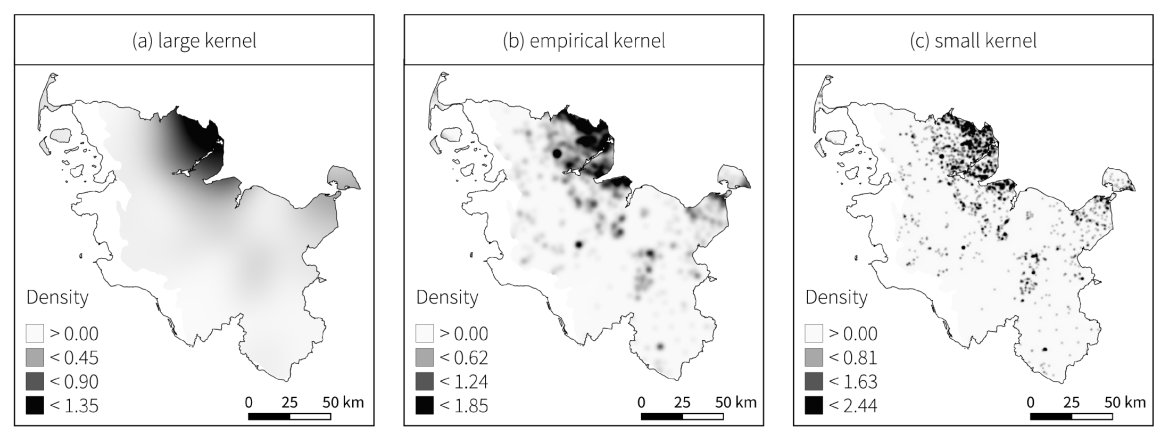

Fig. 4: Kernel density estimation of megalithic graves in Schleswig-Holstein; density values correspond to megaliths per square kilometre; different absolute values are due to the kernel weighting process

\subsection{Distance based analyses of megalithic graves}

The calculation of the distance functions provides homogeneous results: all of them show a strong deviation from the theoretical distribution of complete spatial randomness. Accordingly, the megaliths are not distributed randomly throughout space (Fig. $5 \mathrm{a}-\mathrm{d}$ ). The results of the G-function show that the distances to the nearest events are shorter than under random conditions without interactions. Nearly all events had their nearest-neighbour within $1000 \mathrm{~m}$. The results of the F-function illustrate that the proportion of events with a small nearest-neighbour distance between a point and an event location is smaller than in the random case. This indicates that there are larger "empty-space" areas in the megalith point pattern than under random conditions. The results of the G- and F-functions that rely on the nearestneighbour distance between points indicate an aggregation of megalithic graves.

The results of the K- and L-functions show that the amount of megalithic graves within smaller radii around graves is higher than in the random case. Hence, events are located closer to each other as it would have been expected in the case without interactions. The K- and L-functions indicate an aggregation of events, hence interaction between the megalithic graves.

The results of the kernel density estimation indicate a general trend within the data. This first-order effect in the point pattern influences the occurrence of megalithic graves. In order to consider this, we adapt the theoretical model to implement the general trend of megalithic graves' density throughout the area. The results 


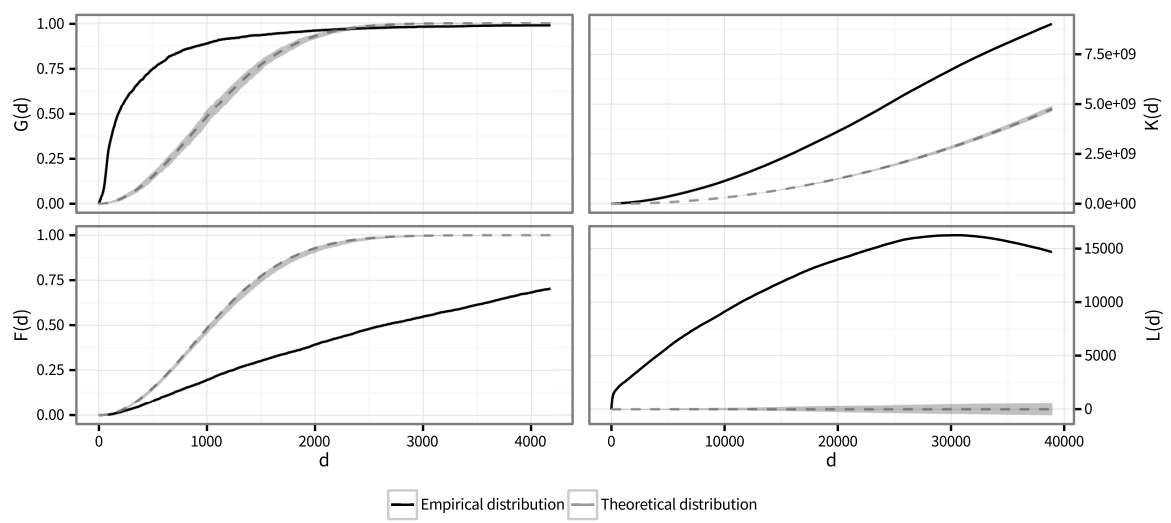

Fig. 5: Results of the distance function calculations for megalithic graves in Schleswig-Holstein; Nearest-neighbour based G- and F-functions (left side) as well as count-circle based K- and L-functions (right side) show deviation from theoretical model of complete spatial randomness and illustrate that the distribution is aggregated.

of the L-function for this inhomogeneous pattern shows still strong deviation from the theoretical model. Nevertheless, the pattern is different: at distances smaller than $5000 \mathrm{~m}$ the megaliths show aggregation while at larger distances they show the opposite trend of a more repelling distribution (Fig. 6).

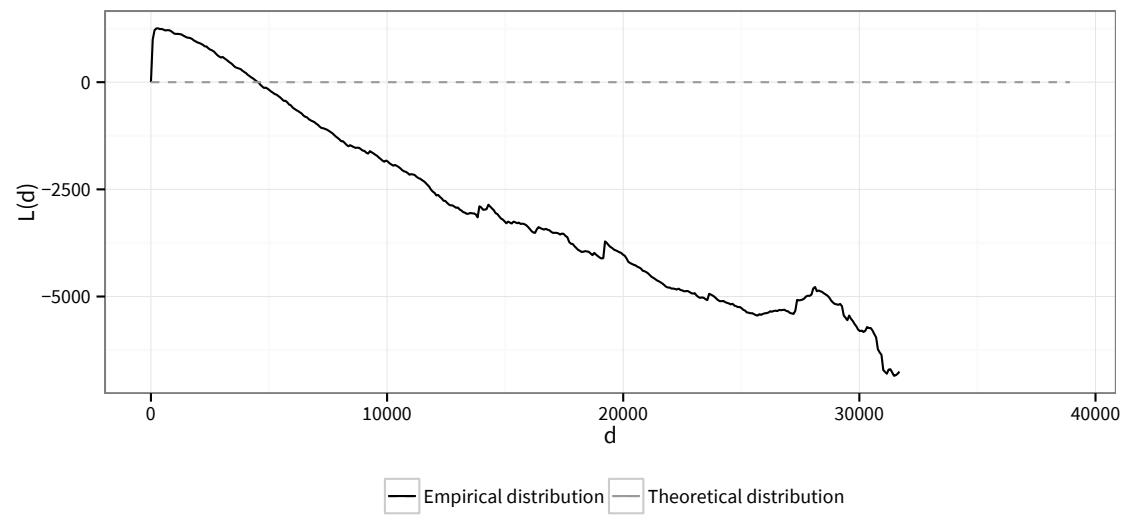

Fig. 6: Inhomogeneous L-function for megalithic graves in Schleswig-Holstein; at short distances a strong clustering occurs, while starting from around $5 \mathrm{~km}$ the opposite behaviour is present; first-order stationary is based on results from general trend within the data (Fig. 4 a) 


\subsection{Geomorphometric parameters}

We compare the locational characteristics of megaliths and artificially created points. The latter are created as resulting from (a) a complete spatial random process (Fig. 7p), (b) a process influenced by first- but not second-order effects (Fig.7p), and (c) a process influenced by first- and second-order effects (Fig.7F).
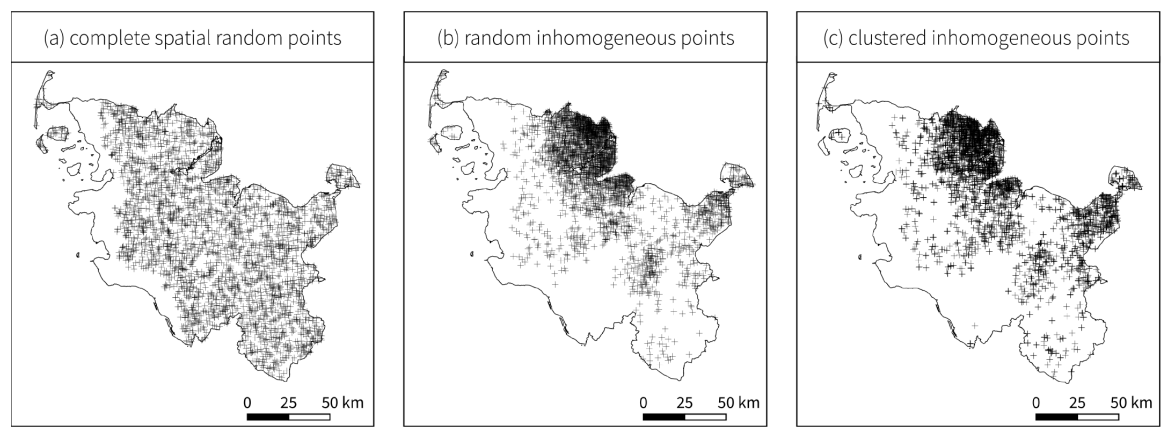

Fig. 7: Artificial point patterns; (a) complete spatial random pattern; (b) pattern with first-order effects; (c) pattern with first- and second-order effects; see text for more details

The values of the different geomorphometric characteristics are extracted within a buffer of $100 \mathrm{~m}$ of the event locations. This is done (a) to take into account that megalithic graves are no points but polygon features, and (b) to enlarge the sample in order to represent locations by more than only one value. The summarising function for the extracted values was median for the continuous raster and modal for the categorical geomorphons raster.

The comparison of elevation values of artificial and empirical events shows that the megalithic graves are located to a certain degree on higher altitudes and that very low altitudes are avoided (Fig. 8). This behaviour is also visible in the firstand second-order influenced artificial point pattern. Besides, there are no clear differences discernible between the artificial point patterns and the megalithic graves.

In case of the Topographic Position Index, the differences in the location of artificial events are few (Fig. 9): although the density differs slightly, the general pattern shows a concentration at values around and below zero what is indicative for flat locations and slopes. The distribution of the megaliths is different. Although the most values are around zero, the distribution is skewed to higher values.

This pattern gets also obvious for the Convergence Index (Fig. 10). The distribution of the megalithic graves is skewed to higher values.

The results of landform classification geomorphons show a clear concentration of the megalithic graves on classes "ridge", "summit", "slope", and "spur". This location preference is not visible in any of the artificial point patterns (Fig. 11) 

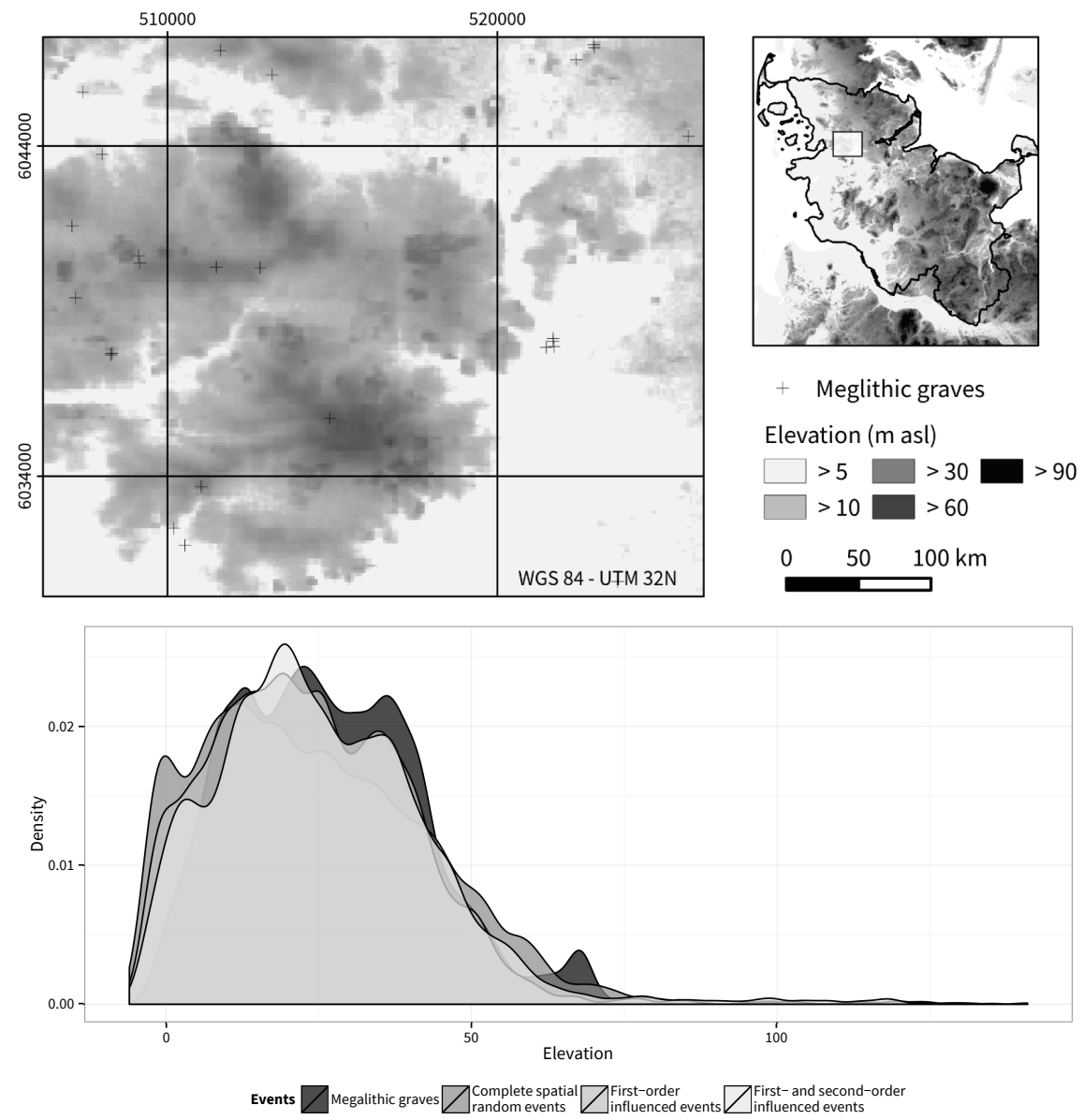

Fig. 8: Digital Elevation Model of Schleswig-Holstein (top) and its probability density for megalithic graves as well as artificial event locations (bottom)

Altogether the results of geomorphometric parameter calculations show the tendency of megalithic graves to be located on elevated positions, i.e. on ridges and summits. Flat areas or pits are avoided as locations. The artificial point patterns do not distinctly diverge from the pattern of the megalithic graves, except for landform classification. 

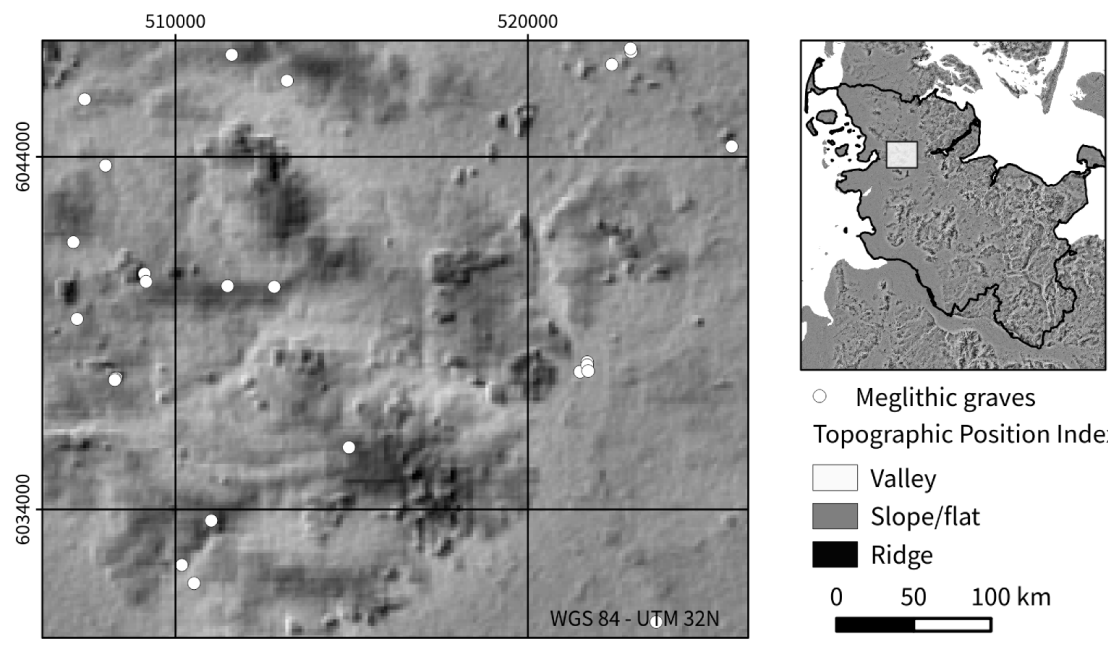

Meglithic graves

Topographic Position Index

$\square$ Valley

Slope/flat

Ridge

$\begin{array}{lll}0 & 50 \quad 100 \mathrm{~km}\end{array}$

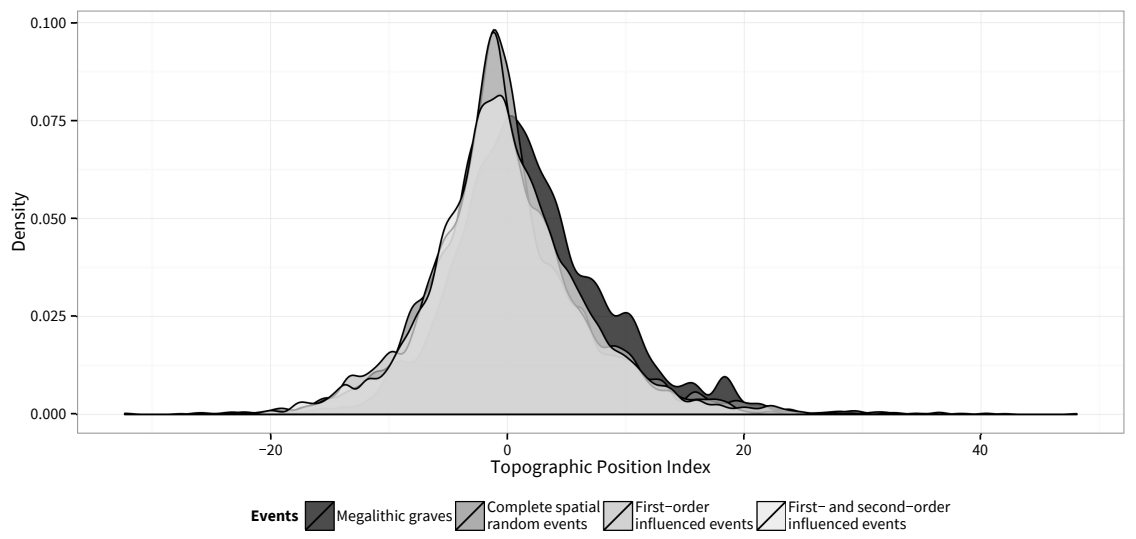

Fig. 9: Topographic Position Index of Schleswig-Holstein (top) and its probability density for megalithic graves as well as artificial event locations (bottom)

\section{Discussion}

\subsection{Density based analysis of megaliths}

The northeast-southwest decreasing trend in the density of megalithic graves continues to the north ([Fritsch et al., 2010] as well as Fig. 2]. The entire area of high density, also referred to as "megalithic heartland" [Müller, 2011, 42], also influences subsequent cultural dynamics where megalithic graves played a different role (see [Furholt, 2012]). Accordingly, it is valid to interpret the general trend reconstructed 

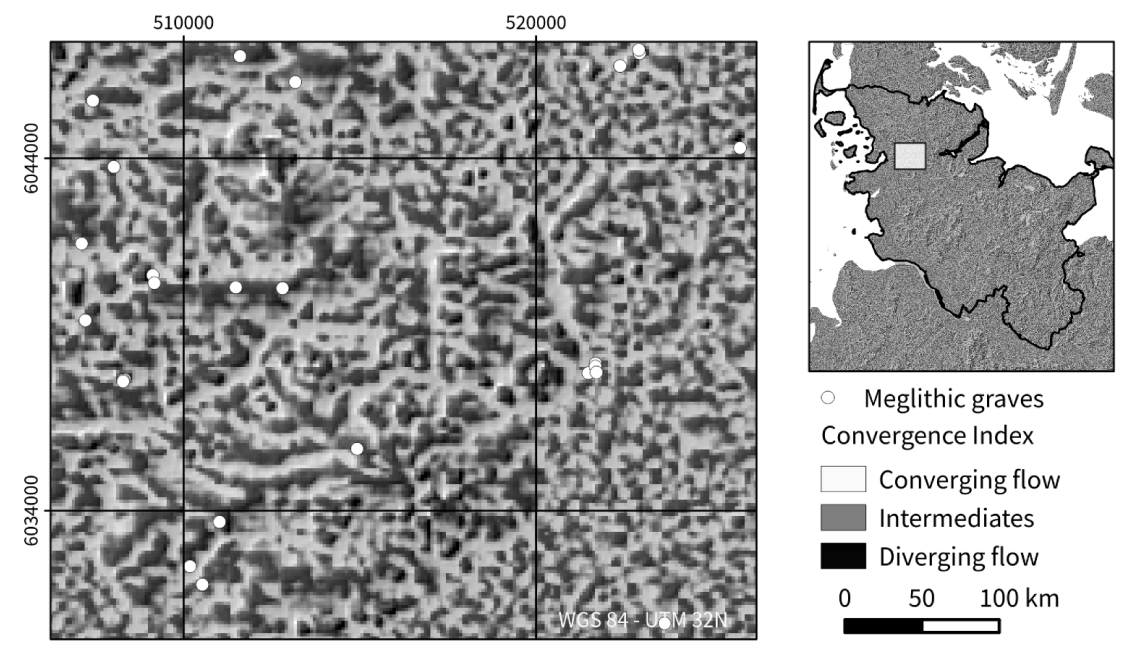

Meglithic graves Convergence Index

$\square$ Converging flow

Intermediates

Diverging flow
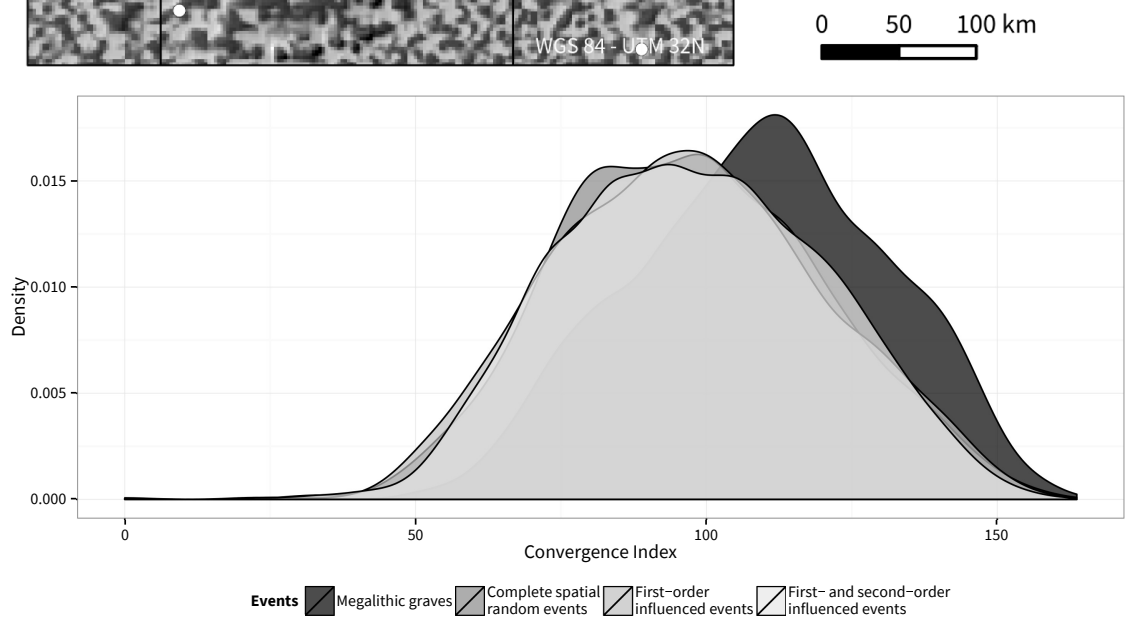

Fig. 10: Convergence Index of Schleswig-Holstein (top) and its probability density for megalithic graves as well as artificial event locations (bottom)

in the data as a first-order effective since it is related to a specific process of societal organisation.

Small and local clusters of high megalithic grave density occur all over the research area (Fig. 4k). This distribution might reflect local favourable living conditions as proposed by local archaeological studies (e.g. [Lüth, 2011]. Nevertheless, since our methods do not integrate this kind of local-scaled but regionally specific information, no further conclusions can be drawn from this observation.

The north-south elongated line of moderate to high densities of megalithic graves (Fig. $4 \mathrm{~b}$ ) that corresponds to the transition between young-moraine and geest areas can be interpreted as an exchange corridor between the north and the south. In terms of environmental characteristics this area is favourable because of small differences 

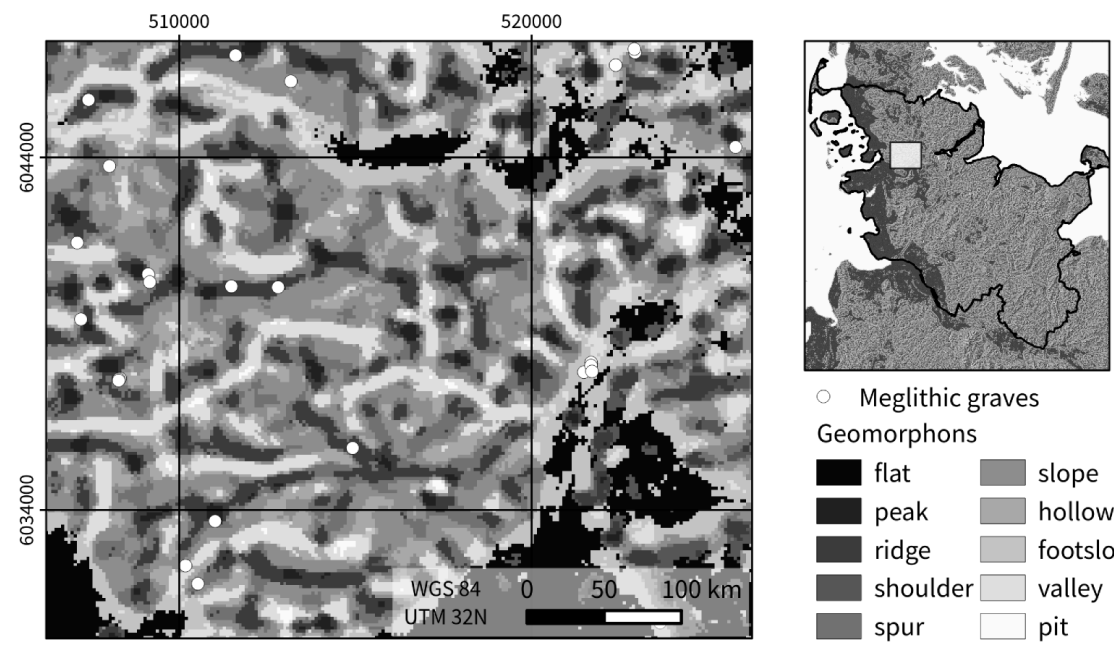

- Meglithic graves Geomorphons
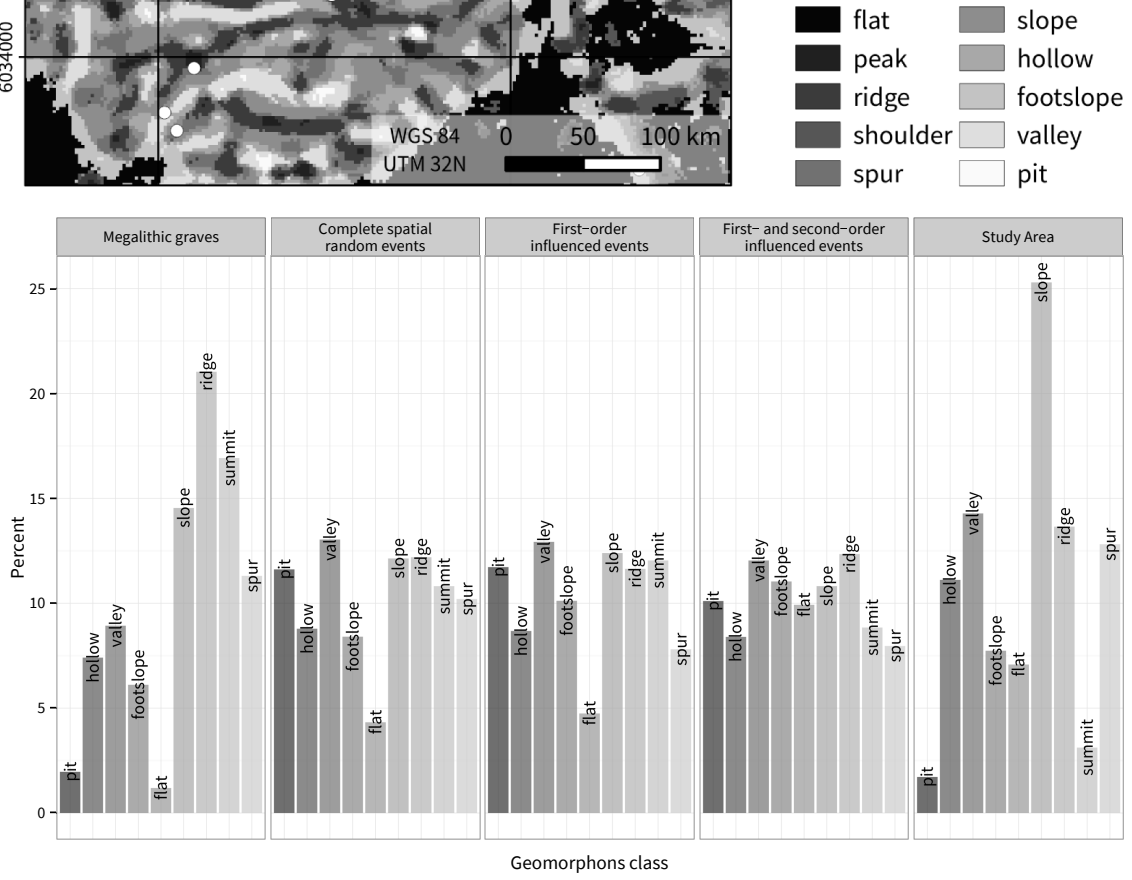

Fig. 11: Geomorphons in Schleswig-Holstein (top); the relative occurrence of megalithic graves as well as artificial events on different geomorphons classes (bottom)

in topography while character of soils remains uniform, being light and well drained. This is the case in the sandur areas [Witt, 1962, 1020]. This favourable situation is also documented by the fact that an old and throughout the millennia always important road—known from medieval times as Ochsenweg [Hill, 2002]—runs here. Hence, the conducted calculations also reflect the tendency of megalithic graves to be located along traffic routes. 


\subsection{Distance based analyses of megaliths}

The nearest-neighbour distances of the megalithic graves are mostly smaller than 1 km (see empirical curves for G- and F-functions in Fig. 5). This characteristic in combination with the facts that (a) the megalithic graves are found in clusters and (b) that these clusters repel one another, concurs well with the observation that megalithic graves are settlement indicators [Lüth, 2011, 119]: Graves are constructed for more than one generation in direct vicinity to settlements. This leads to their clustered distribution. Furthermore, since each settlement needs a certain kind of space to sustain living conditions-i.e. at least $4 \mathrm{~km}$ as shown by empirical studies [Chisholm, 2007, 146] - they tend to push potential space-competitors away. Accordingly, the clusters of megaliths show a repelling behaviour at this critical distance (Fig. 6).

\subsection{Geomorphometric parameters}

The results of the spatial analysis of the different geomorphometric parameters, especially those of the Topographic Position Index (TPI), are influenced by measurement errors of the radar satellite due to forest vegetation (see e.g. [Shortridge and Messina, 2011 1582,1583]). Although there are methods to remove these and other errors (e.g. [Gallant et al., 2012]) we chose to accept them because they do not influence the results in a way that necessitate and therefore justify additional analysis steps.

The geomorphometric parameters' characteristics of the different artificial and empirical point patterns show that not all of them yield information on the characteristics of megalithic graves. The continuous scaled geomorphometric parametersDEM and TPI—do not produce results with pronounced differences. Detailed statistical tests and further parameters would be necessary in order to signify the slight skew to higher values, i.e. ridge-like positions, a topic that would necessitate an own contribution. The last point holds in general also true for the Convergence Index. Nevertheless, the distributions show marked differences. The Convergence Index as used here is focused on topographic features with a smaller spatial extent than the TPI. Hence, although both measure in general the same, i.e. the tendency of a location to be above or below its immediate surroundings, their explanatory value for the megalithic graves is different. This indicates that measures, aiming to describe the locational characteristics of megalithic graves need to be specific on a local level. This holds true for the geomorphons algorithm as employed here. Accordingly, the results show marked differences between the different artificial and empirical point pattern.

Artificial and empirical point patterns differ in terms of their geomorphometric characteristics what indicates that megalithic graves are positioned on certain positions in the landscape. Although the artificial events exhibit the same patterns as the megalithic graves-clustering at short, repelling at larger distances-they are not able to reconstruct the preference of ridge-like positions with good visibility. 
This preference — as also proven by archaeological studies [Lüth, 2011] — could be described by implementing further, more social-related parameters. A future task.

\section{Conclusions}

In this study we present different spatial analytical tools that are useful in areas where detailed local information is absent. In order to conduct spatial analyses we need to be aware of the particularities of spatial data, i.e. spatial autocorrelation, the problem of modifiable areal units, ecological fallacy, scale, and non-uniformity of space. Each research design involves different aspects of these particularities and it is important to recognise that due to this fact, not just research question, data and method but also the research design will influence a study's result.

The simple workflow presented here integrates methods from point pattern as well as geomorphometric analysis in order to detect the potential processes that caused the distribution of points in space. Our points are megalithic graves of Funnel Beaker societies in the area of Schleswig-Holstein, Germany. The results lead to insights on different scales. On a supra-regional scale the graves' distribution follows a trend of decreasing density from northeast to southwest. Thanks to archaeological investigations we can conclude that this trend reflects the increasing distance to the core-area of the Funnel Beaker societies. On a regional scale the distribution shows strips of relative high event density. These prove to be zones of interaction along exchange corridors that are environmentally favourable. On a local scale, comparing our results with local studies, the events' characteristics show clustering at short and repelling at larger distances. Both are linked to the fact that they are located next to settlements. On the one hand they show the intention to minimise distance between grave and settlement, on the other hand they are an indirect proxy of the settlements' need to sustain a sufficient large hinterland for their subsistence.

The comparison of the geomorphometric characteristics of megalithic graves with artificial events to identify certain spatial processes shows that the location of the megalithic graves focus on specific topographic features, i.e. elevated positions with high visibility. This spatial interdependency is also known from local studies, what proves the results from the analyses of geomorphometric site characters.

Altogether methods of point pattern analysis in combination with geomorphometric measures gain multiple insights into the processes that caused an observed distribution of points. The high correspondence between the results of archaeological analysis and ours documents that the presented methodological workflow is especially useful where such information are absent. Hence, it is a promising tool for digital geoarchaeology. 


\section{Acknowledgements}

Daniel Knitter is grateful to the Excellence Cluster Topoi - The Formation and Transformation of Space and Knowledge in Ancient Civilizations for supporting this study.

\section{References}

Ahnert, 1981. Ahnert, F. (1981). Über die Beziehung zwischen quantitativen, semiquantitativen und qualitativen Methoden in der Geomorphologie. Zeitschrift für Geomorphologie N. F., Supplement Band 39:1-28.

Ahnert, 2003. Ahnert, F. (2003). Einführung in die Geomorphologie. Eugen Ulmer, Stuttgart.

Baddeley and Turner, 2005. Baddeley, A. and Turner, R. (2005). Spatstat: an R package for analyzing spatial point patterns. Journal of Statistical Software, 12(6):1-42. ISSN 1548-7660.

Baddeley and Turner, 2015. Baddeley, A. and Turner, R. (2015). Spatstat Manual. CRAN.

Baddeley et al., 2000. Baddeley, A. J., Møller, J., and Waagepetersen, R. (2000). Non- and semiparametric estimation of interaction in inhomogeneous point patterns. Statistica Neerlandica, 54(3):329-350.

Bivand et al., 2015. Bivand, R., Keitt, T., and Rowlingson, B. (2015). rgdal: Bindings for the Geospatial Data Abstraction Library. R package version 0.9-2.

Bivand et al., 2008. Bivand, R. S., Pebesma, E. J., and Gómez-Rubio, V. (2008). Applied Spatial Data Analysis with R. Springer, New York.

Borcard et al., 2011. Borcard, D., Gillet, F., and Legendre, P. (2011). Numerical Ecology with R. Springer New York, New York, NY.

Böhner et al., 2006. Böhner, J., McCloy, K. R., and Strobl, J., editors (2006). SAGA - Analysis and Modelling Applications. Göttinger Geographische Abhandlungen 115.

Chisholm, 2007. Chisholm, M. (2007). Rural Settlement and Land Use. Hutchinson, London.

De Reu et al., 2013. De Reu, J., Bourgeois, J., Bats, M., Zwertvaegher, A., Gelorini, V., De Smedt, P., Chu, W., Antrop, M., De Maeyer, P., Finke, P., Van Meirvenne, M., Verniers, J., and Crombé, P. (2013). Application of the topographic position index to heterogeneous landscapes. Geomorphology, 186:39-49.

Diggle, 2013. Diggle, P. J. (2013). Statistical Analysis of Spatial and Spatio-Temporal Point Patterns, Third Edition. Chapman and Hall/CRC, 3 edition edition.

Fritsch et al., 2010. Fritsch, B., Furholt, M., Hinz, M., Lorenz, L., Nelson, H., Schafferer, G., Schiesberg, S., and Sjögren, K.-G. (2010). Dichtezentren und lokale Gruppierungen - Eine Karte zu den Großsteingräbern Mittel- und Nordeuropas. Journal of Neolithic Archaeology, 0(0).

Furholt, 2012. Furholt, M. (2012). Monuments and Durable Landscapes in the Neolithic of Southern Scandinavia and Northern Central Europe. In Furholt, M., Hinz, M., and Miscka, D., editors, "As time goes by?" Monumentality, Landscapes and the Temporal Perspective. Proceedings of the International Workshop "Socio-Environmental Dynamics over the Last 12,000 Years: The Creation of Landscapes II (14th-18th March 2011)" in Kiel, number 206 in Universitätsforschungen zur prähistorischen Archäologie, pages 115-132. Habelt, Bonn.

Gallant et al., 2012. Gallant, J. C., Read, A. M., and Dowling, T. I. (2012). Removal of Tree Offsets from SRTM and other Digital Surface Models. ISPRS - International Archives of the Photogrammetry, Remote Sensing and Spatial Information Sciences, XXXIX-B4:275-280.

Guisan et al., 1999. Guisan, A., Weiss, S. B., and Weiss, A. D. (1999). GLM versus CCA spatial modeling of plant species distribution. Plant Ecology, 143(1):107-122.

Hijmans, 2015. Hijmans, R. J. (2015). raster: Geographic Data Analysis and Modeling. R package version 2.3-40. 
Hill, 2002. Hill, T. (2002). Von Wegen: auf den Spuren des Ochsenweges (Heerweg) zwischen dänischer Grenze und Eider. Number 12 in Flensburger regionale Studien. Inst. für Geographie und ihre Didaktik, Landeskunde und Regionalforschung, Flensburg.

Illian et al., 2008. Illian, J., Penttinen, A., Stoyan, H., and Stoyan, D. (2008). Statistical Analysis and Modelling of Spatial Point Patterns. John Wiley \& Sons, West Sussex.

Jarvis et al., 2008. Jarvis, A., Reuter, H. I., Nelson, A., and Guevara, E. (2008). Hole-filled seamless SRTM data V4, International Centre for Tropical Agriculture (CIAT).

Jasiewicz and Stepinski, 2013. Jasiewicz, J. and Stepinski, T. F. (2013). Geomorphons - a pattern recognition approach to classification and mapping of landforms. Geomorphology, 182(0):147-156.

Knitter et al., 2014. Knitter, D., Nakoinz, O., Del Fabbro, R., Kohlmeyer, K., Meyer, M., and Schütt, B. (2014). The Centrality of Aleppo and its environs. eTopoi. Journal for Ancient Studies, 3:107-127.

Koethe and Lehmeier, 1996. Koethe, R. and Lehmeier, F. (1996). SARA - System zur Automatischen Relief-Analyse. User Manual. Dept. of Geography, University of Goettingen, unpublished.

Kvamme, 2006. Kvamme, K. L. (2006). There and Back Again: Revisiting Archaeological Location Modeling. In Mehrer, M. W. and Wescott, K. L., editors, GIS and Archaeological Site Location Modeling, pages 2-34. Taylor \& Francis.

Legendre and Legendre, 2012. Legendre, P. and Legendre, L. (2012). Numerical ecology. Number 24 in Developments in environmental modelling. Elsevier, Amsterdam, third english edition edition.

Liedtke and Marcinek, 2002. Liedtke, H. and Marcinek, J., editors (2002). Physische Geographie Deutschlands. Perthes Geographie-Kolleg. Klett-Perthes, Gotha [u.a.], 3., überarb. und erw. aufl edition.

Litt et al., 2007. Litt, T., Behre, K.-E., Meyer, K.-D., Stephan, H.-J., and Wansa, S. (2007). Stratigraphische Begriffe für das Quartär des norddeutschen Vereisungsgebietes. Eiszeitalter und Gegenwart, 56(1-2):7-65.

Lloyd, 2011. Lloyd, C. D. (2011). Local Models for Spatial Analysis. CRC Press, Boca Raton.

Lüth, 2011. Lüth, P. (2011). Die neolithische Besiedlung des nördlichen Schleswig-Holsteins am Übergang vom Früh- zum Mittelneolithikum. Offa. Berichte und Mitteilungen zur Urgeschichte, Frühgeschichte und Mittelalterarchäologie, 65/66 (2008/2009):93-133.

Meynen and Schmithüsen, 1962. Meynen, E. and Schmithüsen, J., editors (1962). Handbuch der naturräumlichen Gliederung Deutschlands, volume Band II. Bundesanstalt für Landeskunde und Raumforschung, Bad Godesberg.

Müller, 2011. Müller, J. (2011). Megaliths and Funnel Beakers: Societies in Change 4100-2700 $B C$. Drieendertigste Kroon-Voordracht, Amsterdam.

Müller, 2014. Müller, J. (2014). 4100-2700 B.C. Monuments and Ideologies in the Neolithic Landscape. In Osborne, J. F., editor, Approaching monumentality in archaeology, The Institute for European and Mediterranean Archaeology distinguished monograph series, pages 181-214. State University of New York Press, Albany.

Neteler et al., 2012. Neteler, M., Bowman, M., Landa, M., and Metz, M. (2012). GRASS GIS: a multi-purpose Open Source GIS. Environmental Modelling \& Software, 31:124-130.

Olaya and Conrad, 2009. Olaya, V. and Conrad, O. (2009). Chapter 12 Geomorphometry in SAGA. In Hengl, T. and Reuter, H. I., editors, Geomorphometry - Concepts, Software, Applications, volume Volume 33 of Developments in Soil Science, pages 293-308. Elsevier.

Openshaw, 1984. Openshaw, S. (1984). The modifiable areal unit problem. Geo Abstracts Univ. of East Anglia, Norwich.

O'Sullivan and Perry, 2013. O'Sullivan, D. and Perry, G. L. W. (2013). Spatial simulation: exploring pattern and process. John Wiley \& Sons Inc, Chichester, West Sussex, UK.

O'Sullivan and Unwin, 2010. O'Sullivan, D. and Unwin, D. (2010). Geographic information analysis. John Wiley \& Sons, Hoboken.

Pebesma and Bivand, 2005. Pebesma, E. and Bivand, R. S. (2005). S classes and methods for spatial data: the sp package. R News, 5(2):9-13. 
Pike et al., 2009. Pike, R., Evans, I., and Hengl, T. (2009). Chapter 1 Geomorphometry: A Brief Guide. In Hengl, T. and Reuter, H. I., editors, Geomorphometry - Concepts, Software, Applications, volume Volume 33 of Developments in Soil Science, pages 3-30. Elsevier.

R Core Team, 2013. R Core Team (2013). R: A Language and Environment for Statistical Computing. R Foundation for Statistical Computing, Vienna, Austria.

Ripley, 2004. Ripley, B. D. (2004). Spatial statistics. Wiley series in probability and statistics. Wiley-Interscience, Hoboken, N.J.

Schmidtke, 1995. Schmidtke, K.-D. (1995). Die Entstehung Schleswig-Holsteins: von der Eiszeit zur Kulturlandschaft. Wachholtz, Neumünster, 3. aufl edition.

Schütt et al., 2002. Schütt, B., Löhr, H., and Baumhauer, R. (2002). Mensch-UmweltBeziehungen in Raum und Zeit-Konzeption eines Fundstellenkatasters für die Region Trier. Petermanns Geographische Mitteilungen, 146(6):74-83.

Shortridge and Messina, 2011. Shortridge, A. and Messina, J. (2011). Spatial structure and landscape associations of SRTM error. Remote Sensing of Environment, 115(6):1576-1587.

Ssymank, 1994. Ssymank, A. (1994). Neue Anforderungen im europäischen Naturschutz. Das Schutzgebietssystem Natura 2000 und die FFH -Richtlinie der EU. Natur und Landschaft, 69(9):395-406.

Stepinski and Jasiewicz, 2011. Stepinski, T. F. and Jasiewicz, J. (2011). Geomorphons - a new approach to classification of landforms. In Geomorphometry 2011, Redlands, Canada.

Stewig, 1982. Stewig, R. (1982). Landeskunde von Schleswig-Holstein. Number 5 in Geocolleg. Borntraeger, Stuttgart, 2., berichtigte aufl edition. 1. Aufl. im Hirt-Verl., Kiel.

Tagil and Jenness, 2008. Tagil, S. and Jenness, J. (2008). GIS-Based Automated Landform Classification and Topographic, Landcover and Geologic Attributes of Landforms Around the Yazoren Polje, Turkey. Journal of Applied Science, 8:910-921.

Thomas, 1949. Thomas, M. (1949). A Generalization of Poisson's Binomial Limit for Use in Ecology. Biometrika, 36(1-2):18-25.

Tobler, 1970. Tobler, W. R. (1970). A Computer Movie Simulating Urban Growth in the Detroit Region. Economic Geography, 46:234-240. ArticleType: research-article / Issue Title: Supplement: Proceedings. International Geographical Union. Commission on Quantitative Methods / Full publication date: Jun., 1970 / Copyright (c) 1970 Clark University.

Verhagen, 2007. Verhagen, P. (2007). Case Studies in Archaeological Predictive Modelling. Leiden University Press.

Weiss, 2001. Weiss, A. (2001). Topographic position and landforms analysis. In Poster presentation, ESRI User Conference, San Diego, CA, pages 200-200.

Wickham, 2009. Wickham, H. (2009). ggplot2: Elegant Graphics for Data Analysis. Springer, New York.

Wiegand and Moloney, 2004. Wiegand, T. and Moloney, K. A. (2004). Rings, Circles, and NullModels for Point Pattern Analysis in Ecology. Oikos, 104(2):209-229.

Wiegand and Moloney, 2013. Wiegand, T. and Moloney, K. A. (2013). Handbook of Spatial Point-Pattern Analysis in Ecology. CRC Press.

Witt, 1962. Witt, W. (1962). Schleswiger Geest. In Meynen, E. and Schmithüsen, J., editors, Handbuch der naturräumlichen Gliederung Deutschlands, volume Band II, pages 1018-1021. Bundesanstalt für Landeskunde und Raumforschung, Bad Godesberg. 